\title{
DESPUÉS DE... UNA HISTORIA DE LA TRANSICIÓN
}

\author{
Después de... A History of the Transition
}

\author{
Elena Blázquez Carretero \\ Universidad de Castilla-La Mancha \\ Elena.Blazquez@uclm.es
}

Fecha de recepción: 22-IV-2014

Fecha de aceptación: 4-V-2104

\begin{abstract}
Resumen: Después de... puede considerarse una de las primeras entregas de urgencia de la realidad de la Transición. Este doble documental de los hermanos Bartolomé, rodado entre 1979 y 1980, se presenta como un acercamiento a diversos sectores de la sociedad espańola que dan su punto de vista, discuten y explican cómo se han visto afectados por los cambios producidos tras la muerte de Franco. Tras el 23-F, el documental quedó varado por la Administración, víctima de una censura encubierta y de un sistema de estrenos simbólicos. Ya fuera por reflejar los cambios que se estaban produciendo a nivel de gente de la calle o por contar aquello que los noticiarios no contaban, el documental sufrió una precaria y tardía distribución. Pese a todas las dificultades encontradas en torno a su exhibición, este testimonio resulta a día de hoy de enorme utilidad para conocer los problemas de entonces y los que aún permanecen.
\end{abstract}

Palabras clave: Cine; Historia; Transición.

Aвstract: Después de... fulfilled an urgent need in its day, being one of the earliest attempts to reflect the reality of the Transition. This double documentary by the Bartolomé siblings was shot in 1979 and 1980, and approaches various sectors of Spanish society, allowing them to express their points of view, and to discuss and explain how they were affected by the changes that took place following the death of Franco. After 23-F, the attempted coup d'état, the documentary was left stranded by the Administration, falling victim to a covert censorship and to a system of unofficial releases. Perhaps because it brought to light the changes affecting 
the lives of ordinary people and the stories that had been neglected by the media, the distribution of the documentary was hampered by a great deal of delay and uncertainty. Despite all the difficulties involved in its screening, the testimonies contained in this documentary now provide very useful insight into the problems of the era and those that remain to this day.

Keywords: Cinema; History; Transition.

SUMARIO: 1. Después de... una historia de la transición. 2. Durante Después de... 3. Antes de Después de... 4. Después de... La batalla de Chile. 5. Después de... un film protagonizado mayoritariamente por la voz ciudadana. 6. Acerca del montaje y el desorden. 7. Lo que no formó parte de la Historia. 8. Bibliografía.

\section{DESPUÉS DE... UNA HISTORIA DE LA TRANSICIÓN}

Después de... comienza con el entierro de Franco, al cerrarse su tumba, con el sonido de la lápida acompańado por la rotundidad de la música de Vytas Brenner. Un final que da comienzo a un principio, que se sitúa aproximadamente tres años y medio después de la muerte de Franco: en el primero de mayo de 1979. La izquierda sale a la calle y asistimos, con motivo del Día del Trabajo, a unas meriendas en la Casa de Campo que antes hubieran sido disueltas. Se hace un recorrido por el presente de 1979 y se muestran diversos lugares de reunión y manifestaciones pertenecientes a diferentes sectores del espectro político. Más tarde, el documental se desplaza por distintos acontecimientos, especialmente relacionados con las autonomías recién establecidas y el surgimiento del neofranquismo, que concluyen, al final de la segunda parte, en la posibilidad involucionista por parte del ejército, citando concretamente a Miláns del Bosch.

Se rueda en dos años, mayoritariamente de abril a diciembre de 1979, con algunas interpolaciones realizadas en 1980; y se narra aquello que acontece frente a la cámara durante ese corto período de tiempo, esa primera Transición. Una historia parcial como cualquier otra, un film-testimonio ${ }^{1}$ que centra su discurso en la gente de la calle. Fernández Colorado habla de un "retablo de la Transición» ${ }^{2}$, de un conjunto de figuras que representan una historia, un pequeño escenario en el que se representa una acción. No representa todo lo que ocurría en aquellos ańos, pero tampoco es un discurso único o sesgado. Se presenta, sin embargo, un paisaje ideológico en el que se escuchan opiniones

1 En el tiempo en el que se rodaba la película, la propia Cecilia Bartolomé detectó esa naturaleza testimonial hacia la que se iba desenvolviendo el film: «No es un documental, es más bien una película-testimonio, sin ningún ánimo de política partidista». Ver: Carlos Galindo, «Entrevista. Cecilia Bartolomé: Película-testimonio sobre el cambio sociológico español», $A B C, 30$ de septiembre de 1979, p. 60.

2 Fernández Colorado, Luis, «El retablo de la Transición», en: Josetxo Cerdán y Marina Díaz (eds.), Cecilia Bartolomé: El encanto de la lógica. Barcelona: La Fàbrica de Cinema Alternatiu. Madrid: Ocho y medio, 2001, pp. 63-73. 
diversas, en muchos casos contrarias, y se contraponen distintos puntos de vista, no sólo en la pantalla a través de la edición, sino también a través de los enunciados de aquellos que expresan su opinión libremente a pie de calle. Existe, tal y como apunta Selva i Masoliver, una «reticencia a la individualización y aún más a la hagiografía de los líderes» ${ }^{3}$, y por ello, aunque aparecen algunos dirigentes políticos, como Felipe González, Santiago Carrillo o Miguel Castells, no es en ellos donde se detiene la cámara o a quien se cede un espacio privilegiado en la sucesión de los acontecimientos.

Los documentos rodados se engloban bajo el mismo título Después de..., después del Franquismo, después de Franco, a quien deliberadamente no se menciona, pero del cual se recuperan dos sentencias a modo de subtítulo para nombrar cada una de las partes en las que se divide el documental: No se os puede dejar solos y Atado y bien atado. Mientras que la primera parte pretende ser un acercamiento a diversos sectores de la sociedad espańola que dan su punto de vista, discuten o explican cómo se han visto afectados por los cambios producidos en el país tras la muerte de Franco, la segunda es ya un análisis político de la Transición, contado por y para la gente de la calle. Ante la cámara pasan políticos, profesionales de distintos ámbitos y ciudadanos de a pie que dan testimonio y expresan sus ideas acerca de los cambios acaecidos en los últimos años, discutiendo y poniendo en cuestión temas como las autonomías recién establecidas, el resurgir del neofranquismo, la incorporación de España a Europa, el terrorismo y el incremento de la escalada de la violencia. De esta manera, el film pretende alejarse del monopolio informativo de la época y mostrar una historia de la Transición española vista y contada desde la calle; facilitando así la reflexión sobre un suceso contemporáneo para poderlo cuestionar y discutir desde distintas perspectivas. En nuestros días se ha convertido, como muchas otras producciones cinematográficas de la época, en una fuente primaria de conocimiento acerca de la Transición, que resulta esencial para comprender muchos aspectos de este período, y sobre todo, acerca de la opinión directa de los ciudadanos.

\section{DURANTE DESPUÉS DE...}

Es importante señalar que ni había un sólido armazón guionístico previo que sustentara el rodaje, ni tampoco una maduración serena sobre lo que estaba ocurriendo. Tal y como contaron los hermanos Bartolomé en entrevistas posteriores a la realización del film, por aquella época estaban trabajando en un guión satírico, al estilo de las producciones anteriores de Cecilia Bartolomé, y se encontraron que, a la hora de su escritura, hablaban mucho más de lo que ocurría en la calle que acerca del guión, por lo que deci-

3 Selva i Masoliver, Marta, «La palabra necesaria. A propósito de Después de... (I y II parte)», en: Josep María Català, Josetxo Cerdán y Casimiro Torreiro (coords.): Imagen, memoria y fascinación. Notas sobre el documental en España. Festival de Cine Español de Málaga/Ocho y medio, Madrid, 2001, p. 274. 
dieron seguir el rumbo de los acontecimientos externos y salir a grabar aquello que estaba sucediendo en el país ${ }^{4}$ Se filmó con una Arriflex CP 16R, una de las cámaras más ligeras y manejables del momento. El negativo utilizado era de dieciséis milímetros, el propio de estos equipos compactos, que se acercaba en parte a la versatilidad de los posteriores equipos de vídeo. El sonido se registró con un Nagra portátil. La ligereza de la cámara y del grabador de sonido permitió que el equipo de rodaje lo formaran un reducido grupo de colaboradores. El equipo básico de rodaje lo componían cuatro personas: el técnico de sonido Bernardo Menz, José Luis Alcaine con la cámara, y Cecilia Bartolomé y José Juan Bartolomé en la dirección, a quienes ocasionalmente acompańaba una quinta persona que actuaba como auxiliar de cámara 5 . En un principio, se recopiló un esbozo de ideas bajo el título provisional de Libertad condicional, «en un obvio juego de doble sentido sobre una democracia amenazada por un sempiterno aparato represivo heredado del franquismo» ${ }^{6}$ que aludía no sólo a la realidad que reflejaba la película sino «también a la situación en la que se encontraba el cine» ${ }^{7}$. Más tarde, se realizó un conato de guión, en el que se incluía un esquema de lo que se quería rodar y se señalaban algunos de los lugares a los que acudir teniendo en cuenta los contactos a partir de los cuales ser informados de movimientos, acontecimientos y acciones importantes para filmar. Ese guión previo se rodó en un cincuenta por ciento, reduciendo a la mitad la duración del montaje definitivo. A pesar de que los hermanos Bartolomé realizaron una ardua labor de montaje de la que quedaron fuera muchas horas de filmación, seleccionando una mínima parte del material rodado y eliminando aquel que resultaba prescindible, varias han sido las críticas acerca de la presentación reiterada de contenidos y la extensión del tiempo de la acción ${ }^{8}$. Lejos de ser así, en la necesidad de dejar que los ciudadanos se expresaran, y en el interés de poder observar un tiempo que, aunque convulso, ocurría despacio, los hermanos Bartolomé pasaban horas entre la gente, dejando que surgiera la conversación y esperando un momento propicio para grabar. Un tiempo en el que, en muchas ocasiones, la primera ilusión y el siguiente desencanto hicieron que el país estuviera cubierto por un halo de incertidumbre que ralentizaba ineludiblemente la acción del presente y se traducía en la pantalla en un dejar pasar el tiempo y una suma de opiniones persistentes

4 Llinás, Francesc y Ferrán Marín, «Los brujos inocentes. Entrevista con Cecilia y José Juan Bartolomé», en: Contracampo, abril-junio 1982, pp. 16, 17.

5 Declaraciones recogidas en el marco del coloquio posterior a la proyección de Después de..., celebrado en las jornadas de Cine y Transición de Memorias en Red; y moderado por la autora. Madrid, 27 de marzo 2014..

6 Fernández Colorado, Luis., ob.cit., p. 66.

7 Bartolomé, Cecilia y José Juan. «Después de..., un espejo que quisieron romper», Guía del Ocio, Madrid, 1 al 7 de junio 1981.

8 En la línea de estas críticas, se recoge la de Fernández Torres, quien indica que parece que: «Después de... ha sido víctima de una peligrosa 'tentación de plenitud'. Ha querido hacer un fresco documental total sobre la transición. De ahí su resistencia a eliminar material informativamente poco relevante y perfectamente desechable». Ver: Fernández Torres, Alberto. «Paisaje después de la batalla», en: Contracampo, abril-junio 1982, p. 14. 
fruto del posterior descontento. Siendo así, resulta bastante improbable que los hermanos Bartolomé sucumbieran a la trampa de la fascinación y alargaran la escena en un fútil intento de recrear un fresco documental total de la Transición.

\section{ANTES DE DESPUÉS DE...}

Salvo en contadas excepciones como en Lejos de los árboles (1970) de Jacinto Esteva ${ }^{9}$, el cine de izquierdas se vio mayoritariamente escudado en la ficción pudiendo desde ahí servirse de alusiones indirectas capaces de sortear los escollos de la censura. Después de esta forzosa y escasa existencia, no es de extrañar que durante la Transición el documental recobrara una fuerza perdida y fuera extensivamente utilizado por anteriores y nuevos realizadores. Proscrito, no sólo formalmente, sino también por su innegable capacidad de situar la imagen en relación directa con su referente, revigorizando así los hechos pasados y presentes bajo una patina de verdad, el documental se pensó en la Transición como un arma política capaz de oponerse al documento oficial y ofrecer alternativas a las historias narradas acerca del pasado y el presente.

Así, muchas de las producciones documentales del momento se volcaron hacía el pasado con el propósito de reconstruir aspectos olvidados de la historia de los últimos cuarenta años y, en algunos casos, de la Segunda República y la Guerra Civil. De la misma manera y con la necesidad de responder a la urgencia de la realidad que se vivía en el presente, se realizaron documentales políticos que se centraban en los últimos años del Franquismo y en los primeros años de la Transición. Tal y como indica Joan M. Minguet, estos documentales políticos, como categoría o subgénero que hoy día ha circunscrito su exigua existencia a la televisión, gozaron entre los años 1976 y 1980 de diversas y eximias representaciones ${ }^{10}$. Así, Después de... (1981) puede compartir un espacio de crónica con La vieja memoria (1977) de Jaime Camino o con el Informe general (...) (1976) de Pere Portabella; a la vez que se convierte en retrato de esos últimos años del Franquismo y de la primera Transición junto con Arriba España! (1976) de José María Berzosa, Entre la esperanza y el fraude (1977) de la Cooperativa de Cine Alternatiu de Barcelona y El proceso de Burgos (1979) de Imanol Uribe. . Más lejana desde el punto de vista formal, aunque no en su espíritu, se situaría El Desencanto (1976), de Jaime

$9 \quad$ Ver: Delgado, Manuel, «El arte de danzar sobre el abismo. Sobre Lejos de los árboles de Jacinto Esteva (1961-1970)» en: Josep Maria Català, ed., Imagen, memoria y fascinación. Notas sobre el documental en España, Consejería de Cultura, Junta de Andalucía, 2001, pp. 221-230.

10 Minguet, Joan M., «Tras el después (El cine, la memoria, el compromiso...)», en: Josetxo Cerdán y Marina Díaz (eds.), Cecilia Bartolomé: El encanto de la lógica. Barcelona: La Fàbrica de Cinema Alternatiu. Madrid: Ocho y medio, 2001, p. 73. 
Chavarri, metáfora de la decepción de un país condenado a chapotear en el desencanto y descontento presente ${ }^{11}$.

En todo caso, y a pesar de sus coincidentes puntos de unión, lo que diferencia a muchos de estos documentales, y especialmente a Después de..., es que mientras muchos de ellos potencian el protagonismo de intelectuales, artistas, antiguos combatientes o dirigentes políticos, el protagonismo del relato de los Bartolomé recae en personas anónimas de las que no se conoce apenas nada, de no ser por los rótulos sobreimpresos que informan acerca del contexto geográfico o profesional de los participantes o entrevistados. Tal y como apuntan Josetxo Cerdán y Marina Díaz en su edición acerca de la filmografía de Cecilia Bartolomé: «Después de..., a diferencia de otros filmes coetáneos, apuesta por hacerse voz y portavoz de la tradición negada de cotidianidad y el anonimato en la vida política» ${ }^{12}$, contribuyendo así a la creación de encuentros para el debate y al registro de opiniones diversas acerca de la vida diaria de los ciudadanos.

\section{DESPUÉS DE... LA BATALLA DE CHILE}

La crítica de aquellos años subrayó también la coincidencia de planteamientos entre la película de los Bartolomé y La batalla de Chile (1972-1979). En esta trilogía que siguió de cerca la experiencia del gobierno de Allende hasta el golpe de Estado de Pinochet, no sólo había participado José Juan Bartolomé como asistente de dirección, sino que también Bernardo Menz, el sonidista chileno que casi siempre los acompañaba en Después de..., había desempeñado el mismo cometido en La batalla de Chile. Más allá de las críticas periodísticas que señalan las conexiones de ambos documentales incidiendo en atribuirle menor fuerza aunque igual demagogia a Después $d e . .{ }^{13}$, resulta interesante conocer la opinión acerca de estos puntos comunes de la mano de aquellos que se vieron envueltos en ambos proyectos.

Bernardo Menz, que había vivido junto a José Juan Bartolomé unos rodajes de cierta similitud en Chile, comentaba asombrado la enorme diferencia que existía entre los dos países. Recuperando sus palabras a través de los hermanos Bartolomé, para él:

11 Tal y como comentaban los hermanos Bartolomé en una entrevista a Contracampo: La película quería preguntarse por el desencanto de la sociedad española tras la muerte de Franco y más aún tras la ilusión que habían despertado las primeras elecciones democráticas de 1977. Ver: Llinás, Francesc y Ferrán Marín, ob. cit., p. 17.

12 Cerdán, Josetxo y Marina Díaz, «Las rozaduras del agua se hacen de manera invisible: pequeña cartografía para transitar por el cine de Cecilia Bartolomé» en: Josetxo Cerdán y Marina Díaz (eds.), Cecilia Bartolomé: El encanto de la lógica. Barcelona: La Fàbrica de Cinema Alternatiu. Madrid: Ocho y medio, 2001, p. 16.

13 Al respecto, Pedro Crespo señala: «A imitación de La batalla de Chile, del allendista Patricio Guzmán, pero sin su fuerza, aunque la iguale en demagogia». En: Pedro Crespo, «'Después de...' de Cecilia y José Bartolomé», $A B C, 10$ de noviembre 1983, p. 72. 
«Los problemas siempre tenían en Chile un tono serio, dramático y monocorde; mientras que aquí siempre había una tendencia hacia el humor en la situación o en el modo de expresarse, un humor a veces muy negro, pero humor...y por supuesto, inesperados excesos $»^{14}$ : un carácter que se podría calificar de esperpéntico en Después de... frente a un tono de mayor gravedad en La batalla de Chile.

Frente a estos cambios de tono y expresión, se observan en ambos documentales claros referentes comunes que reflejan las contradicciones inherentes a un país que se encuentra enfrentado a un replanteamiento de su pasado y una incertidumbre acerca de su futuro. Tal y como señala Fernández Colorado, en Después de... el planteamiento fundamental, al estilo acuñado por La batalla de Chile: «buscaba desarrollar una estructura dúplice que reflejase el progresivo divorcio entre sociedad y estamento político, atravesada a su vez por temas de rabiosa actualidad como la ańoranza del pasado, la marginación de la juventud, el fantasma del paro, la modernidad de los nuevos sacerdotes cristianos, la escalada de atentados terroristas, las rebeliones contra el centralismo o el inmovilismo progolpista de los militares ${ }^{15}$. Como en el caso de La batalla de Chile, los hermanos Bartolomé empezaron filmando los logros de una sociedad en transformación y acabaron filmando una sociedad en peligro de involución como el que supondría el golpe de Estado de Pinochet y después el golpe de Estado del 23-F.

\section{DESPUÉS DE... UN FILM PROTAGONIZADO POR LA VOZ CIUDADANA}

Frente a las posibles caídas en mistificaciones asociadas al cineasta de izquierdas, como la creencia de la cámara como un supuesto testigo mudo, neutral y veraz de lo que le rodea, Después de... se muestra no como una única supuesta lectura de una realidad impuesta de manera autoritaria al espectador, sino como un poliédrico montaje del desencanto y el descontento ciudadano. Fernández Torres seńala que «el film no cae en la ilusión de hacerle creer al espectador que quien habla es la realidad, sino que subraya que quien habla es el propio film». En este sentido ponía un ejemplo muy acertado: en el rodaje de la manifestación del 28 de febrero de 1979, Día de Andalucía, la cámara siempre se sitúa en el punto de vista de los agredidos (los manifestantes) y contra el punto de vista de los agresores (Fuerza Nueva, primero y las Fuerzas del Orden Público, después) ${ }^{16}$.

Así es como en este polifónico largometraje de la Transición se recogen entrevistas en directo no preparadas, o mediante registros visuales y sonoros, que son en muchos

14 Declaraciones recogidas en el marco del coloquio posterior a la proyección de Después de..., celebrado en las jornadas de Cine y Transición de Memorias en Red; y moderado por la autora. Madrid, 27 de marzo 2014.

15 Fernández Colorado, Luis, ob. cit.

16 Fernández Torres, Alberto, ob. cit, p. 14. 
casos fruto de la oportunidad de los sucesos que ocurren frente a la cámara, pero que a su vez responden a unas inquietudes particulares y a un deseo de mostrar ciertos aspectos de la realidad frente a otros. Este es el caso de la secuencia del cura que atraviesa una manifestación de agricultores zamoranos al grito de ¡Viva Fuerza Nueva! provocando una discusión y un posterior incidente con los trabajadores. En ese momento los hermanos Bartolomé ya habían guardado la cámara y volvieron a ponerse a rodar, desde lejos, la representación de esa divergencia de opiniones y el consecuente enfrentamiento verbal hasta su disolución ${ }^{17}$. Otro claro ejemplo de ello serían las declaraciones acerca de los presos protagonizadas por los Hijos del Agobio de Vallecas. Lejos de ingenuamente creer que aquello surgió de un cúmulo de circunstancias, del estar allí y entonces, es importante conocer que los hermanos Bartolomé pasaban horas entre la gente, conversando y conociendo sus inquietudes; y en muchos casos, no era sino después, que se grababa o se renunciaba a grabar.

\section{ACERCA DEL MONTAJE Y EL DESORDEN}

El montaje corrió a cargo de Javier Morán, encadenado al proyecto durante los ańos que duró el rodaje. De manera paralela, se filmaba y poco tiempo después se montaba, intentando trabajar de manera continua en la realización y la post-producción del film para reducir así el tiempo de trabajo y por lo tanto, los costes. Se acumularon horas de filmación, y todo ese material se organizó con una pretensión de uniformidad. Se pretendían intercalar discursos de izquierda y de derecha, escuchar las voces de diversos representantes políticos y las de los ciudadanos discutiendo a favor y en contra de distintos asuntos. No se buscaba crear el orden en el desorden, ni tampoco presentar una situación sin orden ni concierto. Pese a la fluidez del engarce de las diversas piezas, que pretendían formar un mosaico de la vida social y política de la época, la organización de los temas abordados fue tildada de caótica. Igualmente "la hipotética ausencia de un discurso propio en beneficio de la aparente mirada libérrima sobre la realidad sería calificada, por la mayor parte de los cronistas, como superficial y vacía de sentido ${ }^{18}$, frente a otros documentales que mostraban un posicionamiento político claro de principio a fin.

Aunque, como ya ha sido mencionado, la mayor parte de la crítica coincidió en asociar al montaje un cierto desorden que ocultaba cualquier tipo de posicionamiento ideológico, desde distintas facciones siempre se intentó incidir en la existencia de una

7 Declaraciones recogidas en el marco del coloquio posterior a la proyección de Después de..., celebrado en las jornadas de Cine y Transición de Memorias en Red; y moderado por la autora. Madrid. 27 de marzo 2014.

18 Fernández Colorado, Luis, op.cit, p. 67. Otro de los que compartió esta posición fue Fernández Torres, quien escribió que el documental «parece estar huérfano de una organización global que lo conciba antes como un todo con sentido que como un precipitado de acontecimientos». Ver: Fernández Torres, Alberto, ob. cit., p. 13. 
visión sesgada y de un tinte claramente político. Pedro Crespo, en el periódico conservador $A B C$, hablaría de una óptica buscadamente crispada y revolucionaria, con un claro acento marxista, denunciando "la intencionalidad evidente» del montaje a la hora de mostrar una demagógica realidad de "crispación excitada, violenta, con gritos, pedradas, quema y desgarramiento de banderas y sentimientos hostiles». Después de... pretendía ser, desde su punto de vista, «el testimonio previo a la catástrofe, a la explosión seguida del incendio, a la revolución que, según sus imágenes, todo el mundo pedía, dado que el franquismo continuaba, la Constitución no era suficiente, los Estatutos vasco y catalán no convencían, aumentaban el paro y la miseria y nadie estaba contento». Para terminar afirmando que, esas por él consideradas diatribas, quedaban oscurecidas y reducidas, por un espeso vaho de realidad sobrepasada, y que los Bartolomé no hacían otra cosa que manipular, y de forma muy evidente ${ }^{19}$.

Otra fuente de disenso ante la supuesta neutralidad del film proviene del otro extremo del arco político. Mikel Insausti, desde el desaparecido diario vasco Egin, subraya el valor casi temerario de los hermanos Bartolomé al tratar una cuestión candente; en primer lugar, por los problemas que traería consigo a la exhibición de la película y en segundo, por la osadía de enfrentarse a temas que conducen inevitablemente a errores, partidismos y posicionamientos tendenciosos. Así, Insausti, refiriéndose específicamente a la segunda parte Atado y bien atado, señala que las opiniones emitidas responden a consignas de partidos y aparecen en muchos casos mediatizadas por titulares de periódico o subrayadas por un comentario que condiciona y parcializa los distintos testimonios $^{20}$. Concluye, sin embargo, afirmando la imposibilidad de crear un relato capaz de contentar a los distintos frentes, ya que todo montaje documental que pretenda incidir en la política postfranquista y sus secuelas está condenado al fracaso, no solamente por las propias limitaciones del formato sino por las enormes presiones de toda índole que pueden culminar con el secuestro de una película.

No sólo las críticas se centraron en un difuso sentido ideológico del montaje; o en la subjetivación del ángulo de la cámara, sino también en el didactismo de una voz en off añadida a última hora, que tal y como apuntaron Cecilia y José Juan Bartolomé, nació de la necesidad de que existiera un hilo conductor, como subrayado de la presunta asepsia ideológica del film ${ }^{21}$. Debido, en un principio, a la tenue intromisión del montaje en la concatenación de los enunciados que exponen quienes son convocados ante el ojo de la cámara y ante el micrófono, los hermanos Bartolomé decidieron introducir esa voz en off, también presente en La batalla de Chile, además de unos rótulos sobreimpresos

19 Crespo, Pedro. ob. cit.

20 Insausti, Mikel. "Después de...' 2a parte: 'Atado y bien atado'. El engaño al hombre de a pie», Egin, 25 septiembre 1981, p. 19.

21 Llinás, Francesc y Ferrán Marín, ob. cit., p. 20. 
que pudieran servir a modo de nota aclaratoria. En muchos casos, estos apéndices se percibieron como un recurso para acentuar la direccionalidad de la respuesta del público, con el fin de incidir en la construcción de una historia que cerraba interpretaciones. Aunque a su favor Selva i Masoliver señala que se trata de una palabra denotativa que se pretende orientadora de los lugares y conflictos y que sabe replegarse a tiempo consciente de su carácter extradiegético ${ }^{22}$, la propia Cecilia Bartolomé nunca ocultó su desagrado hacia esa voz en off que restaba protagonismo a la voz directa, elemento en un principio clave del film: «A mí, personalmente, cada vez me gusta menos. Pienso que fue un error fruto de la coyuntura. Nos dio un poco de miedo que quedaran las cosas poco claras y optamos por este recurso 'clarificador' que le confiere al film un didactismo que no perseguíamos $»^{23}$.

\section{LO QUE NO FORMÓ PARTE DE LA HISTORIA}

Un ejemplo de aquello que no formó parte de la historia de la película pero sí de la historia de aquellos años fueron algunos aspectos delicados del período postfranquista como torturas, asesinatos a civiles o extradiciones. Tampoco tuvieron cabida el régimen penitenciario, al menos en el caso de presos comunes; ni las luchas obreras. Ante estas inevitables ausencias, José Juan Bartolomé arguye que estaban un tanto limitados por la coyuntura histórica: «Lo cierto es que si hubiera habido alguna importante movilización durante este tiempo en el que trabajamos en la película, allí habríamos estado» ${ }^{24}$, mientras que tangencialmente en lo que se refiere a los presos queda patente como un problema del momento al ser comentado de manera precisa por los Hijos del Agobio.

En última instancia se presenta la posibilidad de poder pensar el montaje del film tras el golpe de Estado y cómo el documental se hubiera desarrollado de haber sido testigo del 23-F. Diego Galán habla de cómo Atado y bien atado se quedó coja al concluirse el primer montaje antes del golpe ${ }^{25}$, pero difícilmente se puede uno referir a un film de incompleto, siendo éste un relato; y como tal, inconcluso y parcial.

Tal y como indican los hermanos Bartolomé, el 17 de febrero de 1981, una vez entregadas las dos copias del film para su clasificación por las Juntas Administrativas a través de un representante en la sede del Ministerio de Cultura, nunca se hubieran podido imaginar que seis días después el Congreso de los Diputados se convertiría en el escenario de una intentona golpista que durante horas convulsionaría al país y haría temer por el estado de una recién nacida democracia. Indudablemente no se puede cono-

\footnotetext{
22 Selva i Masoliver, Marta, ob. cit., p. 273.

23 Llinás, Francesc y Ferrán Marín, ob. cit.

24 Llinás, Francesc y Ferrán Marín, ob. cit.

25 Galán, Diego. «Nuestra reciente historia», El Pais, 7 noviembre 1983, p. 36.
} 
cer qué hubiera ocurrido de haber esperado a entregar la cinta una semana después, y haber presenciado el 23-F, una vez que en el film se había barajado la posibilidad de lo acontecido, incluso citando premonitoriamente a Miláns del Bosch.

Después del golpe, los hermanos Bartolomé pensaron en avanzar una tercera parte, que hubiera re-escrito los dos documentales anteriores, y que llevaría por título: Todos al suelo ${ }^{26}$. Esta tercera parte que no formó parte del documental pero sí de la Historia, quedó interrumpida por los múltiples suspensos administrativos que colapsaron la distribución de las dos primeras partes de la película ya que, poco después del golpe, el documental no sólo no fue retenido sino también perseguido por diversos medios legales, que le condujeron a enfrentarse a graves problemas de comercialización.

El funcionamiento de la censura industrial dificultaba no sólo que los documentales fueran producidos por agentes distintos a los propios cineastas; sino que también obstaculizaba su posterior distribución y exhibición. Esto llevó en algunos casos a su supresión de proyección, como le ocurrió al Proceso de Burgos (1979) o a su procesamiento judicial como en el caso de Rocío (1980) de Fernando Ruiz de Vergara. A ellas se sumaba Después de..., que sufrió al igual que el documental de Imanol Uribe trabas administrativas de cara a su exhibición pública. La Junta de Valoración Técnica -formada, entre otros, por los productores J. L. Tafur y José Samano, los directores Miguel Picazo, Carlos Serrani de Osma, Fernando Méndez-Leite y el documentalista López Clemente- decidió negarle a Después de... cualquier posible subvención oficial arguyendo que más del cincuenta por ciento del metraje era «material de archivo o de encuestas y reportajes, sin especiales valores artísticos, culturales, o sociales ${ }^{27}$. En realidad, eran pocas las imágenes provenientes de archivo, ya que tan sólo se contaba con algunos documentos del Colectivo de Cine de Madrid o algunas imágenes, como aquellas que se incorporaron al inicio del film: las referentes a la muerte de Franco.

Esta nueva forma de censura, entendida por los Bartolomé como un secuestro administrativo, dejó la película «maldita» durante años ya que sin la necesidad de la expeditiva censura del Franquismo, se consiguió silenciar un filme utilizando sanciones económicas y amenazas legales mucho mas sofisticadas ${ }^{28}$. Así, el Ministerio de Cultura prohibió terminantemente que la película se estrenase en ese momento, lanzando la amenaza de pasar al Ministerio Fiscal en caso de estreno. Ante esta situación estaba claro que la distribuidora Suevia Films evitaría conflictos, estrenando la película simbólica-

26 Declaraciones recogidas en el marco del coloquio posterior a la proyección de Después de..., celebrado en las jornadas de Cine y Transición de Memorias en Red; y moderado por la autora.. Madrid, 27 de marzo 2014.

27 Véase el expediente número 228-80N conservado en el Archivo General de la Administración Civil del Estado.

28 Bedoya, Juan G., «Después de..., documental sobre la Transición Española, ha sido desposeído de las subvenciones estatales», El País, 7 de mayo 1982. 
mente después de su éxito en el Festival de San Sebastián y la Semana de Cine de Barcelona. Fue así, en 1981, únicamente exhibida en el marco de la 29 edición del Festival de cine de San Sebastián el 23 de septiembre de 1981 y, un mes más tarde, en la Semana internacional de cine de Barcelona, donde ganó el premio en la sección documentales «por constituir una representación lúcida, inquietante y amarga de la actual situación política espańola» ${ }^{29}$.

No fue sino hasta 1983, tras las elecciones generales, que la Dirección General de Cinematografía rehabilitó Después de... además de El Proceso de Burgos. Una nota de la Dirección General señalaba que los tres filmes (teniendo en cuenta las dos partes de Después de...), al haber sido revocados de las subvenciones anteriores, recibirían la subvención que les correspondía, con cargo a fondo de protección de la cinematografía, así como el derecho a optar a los premios de Especial Calidad o Nuevos Realizadores. En este caso, fuentes de la Dirección General de Cinematografía afirmaron que igual que la anterior discriminación gubernamental de la película había sido una decisión política, también su rehabilitación obedecía a criterios políticos. Finalmente, ocho meses después de ser rehabilitada y tres años después de finalizado el rodaje, se estrenó precaria y tardíamente Después de... en Madrid, el 7 de noviembre de 1983, por iniciativa de la sala Cinestudio Groucho, tras haberse estrenado casi clandestinamente en otras ciudades españolas. En todo caso y a pesar de su estreno postergado, todas esas presiones directas $\mathrm{o}$ indirectas anteriormente sufridas, surtieron efecto sobre su distribución posterior, acrecentando el desinterés de la distribuidora por luchar por exhibir un film tachado oficialmente de difícil, molesto e inoportuno y que, además, no iba a contar con la subvención del quince por ciento de taquilla.

El resultado fue claro: pasados tres ańos, lo narrado era historia y la película lo era quizás también ${ }^{30}$. Se silenció un film que pertenecía a un tiempo anterior, reflejo del mismo y que tenía sentido exhibido en él. Tal y como señalaba Galán: «aunque quizás ya no fuera repetible la aventura que habían corrido los Bartolomé entre los censores recalcitrantes, es importante tener en cuenta esta censura no sólo para matizar el contenido de la segunda parte, sino para ańadirla imaginariamente a la propia película, puesto que aquella actitud reflejaba también con precisión el país que teníamos ${ }^{31}$ ». Se podría hablar, por lo tanto, desde su contenido así como desde su sufrida censura encubierta, de un documento único sobre los acontecimientos políticos y sociales que se sucedieron en el país en los años que siguieron al desengranaje de la Dictadura franquista y su ineludible presencia soterrada durante la primera Transición.

29 Acta del jurado. Semana internacional de cine de Barcelona. Barcelona, 18 de octubre 1981.

30 Fernández-Santos, Ángel, «'Después de...'obra 'maldita' del cine de la transición, se estrena con tres ańos de retraso", El País, 3 noviembre 1983, p. 27.

31 Galán, Diego, ob. cit. 
Pese a su precaria y tardía exhibición, en décadas posteriores Después de... se pasó con notable éxito en universidades, filmotecas y ciclos especiales; además de en televisión, algo que los hermanos Bartolomé perseguían con el fin de hacerla finalmente accesible a un mayor número de espectadores. Aunque no se trata de un documento particularmente exitoso a nivel económico, ni tampoco ha sido protagonista de numerosos estudios, se podría considerar que no existe un documental tan amplio, con un análisis sociológico de esta época de la historia de España que resulte tan completo en términos de dar a conocer la opinión de los ciudadanos acerca de lo que estaba sucediendo, desde un punto de vista tan cercano, y no por ello menos complejo.

Por lo tanto, y considerándolo así, tal y como afirma Selva i Masoliver, se hace necesario, como parte de ese ruido democrático que es la democracia, «reivindicar la posibilidad de que este material esté a mano para ser visionado tanto en un sentido divulgativo como de investigación" ya que "se trata de un material que nos recuerda que las cosas tienen consecuencias, que lo que desde muchos sectores se reivindica en términos de mejoras laborales, sociales, educativas y culturales tienen una tradición que el aquí y ahora televisivo deja en suspensión ahistórica ${ }^{32}$. Ante esta desmemoriada España, que tanto preocupaba a Américo Castro, Después de...y otros relatos coetáneos de la Transición pueden aún, a día de hoy, contribuir a esa especie de amnesia histórica que se ha impuesto e impone a los ciudadanos.

\section{BIBLIOGRAFÍA}

Acta del jurado. Semana internacional de cine de Barcelona. Barcelona, 18 de octubre 1981.

Bartolomé, Cecilia y José Juan. «Después de..., un espejo que quisieron romper». Guía del Ocio, Madrid, 1 al 7 de junio 1981.

Bedoya, Juan G., «Después de...documental sobre la Transición Española, ha sido desposeído de las subvenciones estatales», El País, 7 de mayo 1982, p. 35.

Cerdán, Josetxo y Marina DÍAZ, «Las rozaduras del agua se hacen de manera invisible: pequeña cartografía para transitar por el cine de Cecilia Bartolomé» en: Josetxo Cerdán y Marina Díaz (eds.), Cecilia Bartolomé: El encanto de la lógica. Barcelona: La Fàbrica de Cinema Alternatiu. Madrid: Ocho y medio, 2001, pp. 13-23.

Crespo, Pedro. «'Después de...' de Cecilia y José Bartolomé», ABC, 10 de noviembre 1983 , p.72.

$\overline{32}$ Selva i Masoliver, ob. cit., p. 276. 
Delgado, Manuel. «El arte de danzar sobre el abismo. Sobre Lejos de los árboles de Jacinto Esteva (1961-1970) en: Josep Maria Català, ed., Imagen, memoria y fascinación. Notas sobre el documental en España, Consejería de Cultura, Junta de Andalucía, 2001, pp. 221-230.

Fernández, Luis, «El retablo de la transición», en: Josetxo Cerdán y Marina Díaz (eds.), Cecilia Bartolomé: El encanto de la lógica. Barcelona: La Fàbrica de Cinema Alternatiu. Madrid: Ocho y medio, 2001, pp. 63-73.

Fernández-Santos, Ángel, «'Después de...'obra 'maldita’ del cine de la transición, se estrena con tres años de retraso». El País, 3 noviembre 1983, p. 27.

Fernández, Alberto, «Paisaje después de la batalla». Contracampo, abril-junio 1982, pp. 13-15.

Galán, Diego, «Nuestra reciente historia». El País, 7 noviembre 1983, p. 36.

Galindo, Carlos, «Entrevista. Cecilia Bartolomé: Película-testimonio sobre el cambio sociológico espańol», $A B C, 30$ de septiembre de 1979, p. 60.

Llinás, Francesc y Ferrán Marín, «Los brujos inocentes. Entrevista con Cecilia y José Juan Bartolomé», en: Contracampo, abril-junio 1982, pp. 16-20.

Insausti, Mikel, «'Después de...' 2a parte: 'Atado y bien atado'. El engaño al hombre de a pie», Egin, 25 septiembre 1981, p. 19.

Minguet, Joan M., "Tras el después (El cine, la memoria, el compromiso...)», en: Josetxo Cerdán y Marina Díaz (eds.), Cecilia Bartolomé: El encanto de la lógica. Barcelona: La Fàbrica de Cinema Alternatiu. Madrid: Ocho y medio, 2001, pp.73-81.

Selva, Marta, «La palabra necesaria. A propósito de Después de... (I y II parte)», en: Josep María Català, Josetxo Cerdán y Casimiro Torreiro (coords.): Imagen, memoria y fascinación. Notas sobre el documental en España, Festival de Cine Español de Málaga/Ocho y medio, Madrid, 2001, pp.271-276. 